\title{
2 Private finance publicly subsidized: the case of Australian health insurance
}

JANE HALL, DENZIL G. FIEBIG AND KEES VAN GOOL

Australia's Medicare is a universal, publicly funded comprehensive insurance scheme that provides all its citizens with free treatment in public hospitals, and subsidizes out-of-hospital medical services and pharmaceuticals. Yet alongside this public insurance there exists a strong private health insurance sector that covers private in-hospital treatment or general (largely dental and other) ancillary services. Policy initiatives implemented since 1997 have provided both incentives and penalties to encourage the uptake of private insurance. The proportion of the population with insurance for hospital treatment grew from around 33\% in December 1996 to a high of $45 \%$ in 2000; it then declined slightly until 2007 and has increased since then to $47 \%$ in December 2015 (APRA, 2016). Consequently, significant public funds have been directed to support the private health insurance industry and, by extension, the private health care sector. Current policies reflect the ambiguities of the electoral popularity of Medicare alongside the push to restrain public spending.

This apparently anomalous situation can only be understood in the context of the contested ground between public and private interests in health care financing. In less than 40 years, from 1970 to 2010, Australia moved through the following approaches to health care financing: voluntary private insurance with public subsidies (pre-1974); publicly financed national universal health insurance (Medibank, 1974-1976); a series of policy changes that returned the system to voluntary, predominantly private, insurance with public subsidies (1976-1984); publicly financed national universal health insurance (Medicare, 1984-1996); publicly financed national universal health insurance with publicly subsidized private health insurance (1996-2006); and publicly financed national universal health insurance with an expanded role for publicly subsidized private health insurance (2006 until time of publication). Following a change of government in 2007, a new direction in health care financing was sought. Interestingly, given the previous focus on the roles of 
public and private financing, the 2007 election was focused on public hospitals and how financing should be shared between Commonwealth (the national government is officially the Commonwealth of Australia) and states, but did not directly address insurance. A further change of government (led by the Liberal-National Party in 2013) reversed much of the agreed reform strategy, leaving the future direction, including the future for private health insurance, uncertain.

The economic rationale for such massive government subsidies in the private health insurance market is far from clear. Certainly, in the lead-up to the 1996 election, there was widespread concern about the affordability of private health insurance; and the Prime Minister of the day suggested that premiums would actually fall. Not surprisingly, this has not happened and premiums have continued to rise faster than general inflation. If anything, dissatisfaction with the value for money of private insurance has grown, in spite of the high level of population coverage. The Minister for Health established a community consultation at the end of 2015. Over 40000 Australians responded to the open consultation (online), which showed that the cost of private health insurance was of greatest concern overall (Department of Health, 2015/2016).

\section{Financing the health system}

Australian health care is primarily financed by governments (both at the national and state levels). The structure of government - Australia is a federation formed from six independent colonies, each of which has retained its own government - and the revenue base affect the responsibilities and financial flows. At federation, the state governments retained their responsibilities and functions unless these were specifically ceded to the national government. The national government has had the power to raise income taxes since the 1940s, which gives it a stronger revenue base. The taxing powers of states are limited and states rely on transfers from national government through both general and special-purpose grants.

Within the health system, around two thirds of total spending is contributed by governments, mostly from general revenue. There is a small specific income tax levy, which was introduced in 1984 to raise the additional funds required to finance universal free public hospital treatment. The original Medicare levy taxed individuals 1\% of their income, with exemptions for low income households. Over time the 
levy has been increased several times including a half a percentage point increase from July 2014 to fund the National Disability Insurance Scheme. The levy currently stands at $2 \%$ and raised around $17 \%$ of Australian Government health spending (AIHW, 2016a).

Special-purpose grants for health were introduced (in 1945) to assist states with the funding of hospitals. Hospitals had been established primarily by charitable and religious organizations; by the early 20th century state governments had a major role in funding them and gradually took control, assuming ownership. These 5-yearly agreements on hospital funding between the Australian government and the states and territories continue as the basis for the funding of state health services, primarily public hospitals, but these agreements also provide the opportunity to establish other national health policies. Also in the 1940s, the Australian government established a national Pharmaceutical Benefits Scheme, initially providing a limited range of drugs at no charge; over time the formulary has grown and co-payments have been introduced.

Nongovernment finance (33\% of total finance) comprises primarily individual out-of-pocket expenses (18.8\%); only $8.4 \%$ of total funds, or about a quarter of the nongovernment share, is raised from private insurance (AIHW, 2016a). The private insurance contribution has been growing steadily over the last decade whereas the relative government share has declined. Private health insurance is highly regulated under a policy whose features were established in the period after the Second World War. Insurance was to be voluntary with no compulsion; medical care would be provided on a fee-for-service basis; there would and should be patient co-payments - hence government could not set or limit medical fees. Further, insurance premiums were to be community rated, with open enrolment (although a few small specialized funds were exempt from this last provision). Further, insurance could only be provided by non-profit organizations, so managing to avoid "unhealthy competition".

These developments occurred against a background of alternative proposals for some form of national health insurance with salaried or capitated payments for medical care, all of which were treated with hostility by the medical profession. This ended in a constitutional challenge to the government powers and the amendment of the Australian Constitution that forbade civil conscription of doctors and dentists. In this way, the architecture of the Australian health care system was established, with public support for private voluntary insurance for 
both hospitals and medical care, and the protection of fee-for-service payments.

There were 36 registered insurance funds in 2016 (APRA, 2016). The larger funds include the organizations initially developed by the hospitals and the doctors as mutual organizations, and the government-owned insurer (Medicare). Smaller funds are often the descendants of earlier friendly societies and workers' cooperatives. Private health insurance policy is the responsibility of the national government; responsibility for monitoring and regulation was transferred in mid-2015 from an independent statutory authority, the Private Health Insurance Administration Council, to the Australian Prudential Regulatory Authority which oversees the financial services sector.

\section{The current mix of health service provision}

Australia spent $10.03 \%$ of its gross domestic product on health in 20142015 , an increase from $8.6 \%$ of gross domestic product a decade earlier (AIHW, 2016a). The three major spending components are hospitals, accounting for $44 \%$ of recurrent spending; primary care accounts for $38 \%$, which includes general practitioner consultations, dental services and pharmaceuticals; and the remaining $22 \%$ is categorized as other medical goods and services. Almost $50 \%$ of the "other" category consists of referred medical services such as specialist consultations, pathology and imaging. Although private health insurers contribute to all three sectors, their biggest contribution is in the hospital sector (AIHW, 2015).

Most medical services are provided by independent private practitioners on a fee-for-service basis. General practitioners play an important gatekeeping role in the system, as referral is essential for any reimbursement of specialist services, including diagnostic tests, and therefore most hospital admissions. People are able to choose their own medical provider. Medicare provides subsidies for privately provided medical services. Where practitioners charge above the Medicare reimbursement rate, the patient faces out-of-pocket payments. The levels of co-payments vary by area of residence and specialty (rural and remote-area residents and patients requiring specialist surgical, medical, or obstetric care and anaesthetics tend to face higher co-payments).

The Pharmaceutical Benefits Scheme is universal and covers a comprehensive range of drugs - around $90 \%$ of all prescriptions written are covered by the Pharmaceutical Benefits Scheme. Since its introduction, 
co-payments have been progressively introduced and stand at (as of July 2016) Aus $\$ 38.30^{1}$ for each prescription item for general beneficiaries and Aus $\$ 6.20$ for those receiving social security benefits, with safety net measures to limit total out-of-pocket exposure. Dental services are almost entirely privately provided, under fee-for-service private practice arrangements. However, there are some public dental services with an emphasis on emergency care for low-income groups.

Public and private hospitals account for $59 \%$ and $41 \%$ of admissions, respectively (AIHW, 2016b). Public hospitals generally have a more complex case-mix and the major teaching and research-intensive hospitals are public. Public hospitals can also admit private patients who, though housed in the same facilities, and treated by the same medical and nursing staff, face charges for hospital and medical services. In 2014-2015, 17\% of public hospital admissions were for private patients, with $79 \%$ of those covered by private health insurance (AIHW, 2016b). Other private admissions are covered by insurance for motor vehicle accidents, workers' compensation, benefits provided to military veterans or through out-of-pocket payments.

The (national) Commonwealth government has the responsibility for providing medical services (Medicare Benefits Scheme) and pharmaceutical benefits (the Pharmaceutical Benefits Scheme). Both programmes are based on the government setting fee rebates or negotiating pharmaceutical prices, but with few, if any, controls on service/prescribing levels. Therefore, both programmes represent open-ended spending commitments. Public hospitals are owned and operated by the six state and two territory governments, which are able to apply constraints to total spending. Costs are met by states and territories with a similar level of Commonwealth contribution, negotiated through 5-yearly agreements between each state government and the Commonwealth Government (now known as the Australian Health Care Agreements).

Private health insurance has been limited to covering private hospital treatment (a supplementary role) and ancillary services, now called general insurance, which typically covers out-of-hospital provision of dental, optical, physiotherapy and other allied health services, which are poorly provided in the public system or are not covered by Medicare (a complementary role). Around $85 \%$ of Australians with private health insurance hold a combined hospital and ancillary services product

1 Australian dollars are used throughout the chapter. 
(PHIAC, 2015a). The type of ancillary services covered and the extent of coverage, usually specified as a spending limit, are detailed according to each policy. Insurers are free to design their own packages; however, once a policy type is on the market it cannot be removed while there are still purchasers of that policy. Private insurance is not allowed for pharmaceuticals as these are covered by the Pharmaceutical Benefits Scheme. However, insurers can make some drugs available before Pharmaceutical Benefits Scheme approval, for example Herceptin for breast cancer treatment, but this is done on a case-by-case basis and not explicitly covered in the policy (Pearce et al., 2012). The idea of a "broader health cover" was developed and enacted in legislation in early 2007. This was intended to enable private health insurance to cover services that are extensions of hospital care (such as providing care following early discharge), substitutes for hospitalization (such as hospital-at-home schemes), or programmes that prevent hospitalization (PHIAC, 2016).

\section{Developments before 1974}

Medical services are provided by independent private practitioners primarily on a fee-for-service basis. The first doctors to arrive in the British colony in 1788 were naval surgeons employed to care for the military and convicts. As the number of free settlers grew, the doctors sought the right of private practice and by 1820 they were able to leave government service and establish full-time private practices. Hospitals began as charitable institutions, which operated nursing facilities for the care of the poor, in which medical practitioners provided their services for free. These Honorary Medical Officers worked otherwise in private, fee-for-service practices and had the highest standing among the medical professionals. Meanwhile, developments in the effectiveness of medical and nursing care had two effects: growth in costs prompted the charities to turn to the government for assistance; and growth in demand spurred the introduction of charges. An intermediate level of care (private medical care with accommodation in a small, multi-bedded room) was available for the respectable working and middle class, and private medical care in a single room for those who could afford (relative) luxury (Crichton, 1990).

Private insurance was established first by the hospitals, in 1932, and then by doctors, in 1946, as a means of reducing the problem of bad 
debts. Government involvement in health insurance was established in the 1950s with the national government introducing subsidies for medical services; these were not paid directly but rather through the private insurance funds, so entrenching private health insurance. Those without insurance could be seen at hospital outpatient clinics free of charge. Patients generally had to queue to access these services and the clinics were often attended by doctors in training and offered limited amenities. Hospitals admitted inpatients under a three-tier system. Free treatment was available but was means-tested, and accommodation for these public patients was in large, multi-bedded (Nightingale-style) wards, where they were regarded as teaching material for students and junior medical staff. Senior doctors donated their services in return for the right to treat their private patients. Private patients were offered two standards of accommodation: intermediate in small, multi-bedded rooms; or private in single rooms. Insurance could be bought for either type of amenity. Those without insurance were required to pay out of pocket. Individuals and families were pursued, through the courts if necessary, to repay their debts. Consequently, people would avoid seeking care until their condition was severe, and many would give false names and addresses if admitted, giving rise to problems with continuity of care. Developments and reforms, even the introduction of Medicare, have not changed these arrangements substantially.

\section{The contest between public and private financing: 1975-1996}

By this time, there were two major political parties in Australia. The Liberal Party, politically conservative, traditionally aligned with business interests, had governed in coalition with the National Party, which represented the interests of the rural sector. The alternative, the Labor Party, was supported by the trade union movement. A change in government in 1972, after 23 years of the conservative coalition in power, ushered in a time of major social change, including the introduction of publicly financed universal health care. Medibank, as the new programme was known, was financed from general taxation, provided universal access to public hospitals at no charge, and a rebate on medical fees of $85 \%$ of the scheduled fee (Duckett, 2007). The organized medical profession resisted the advent of "socialized medicine" and the political conflict delayed the introduction of Medibank until 1975 (Crichton, 1990; Scotton, 2001). Private health insurance funds continued to operate 
with community-rated premiums and open enrolment, although their membership base was steadily declining. Soon after Medibank became operational there was a further change in government, amid intense political instability. The conservative coalition returned to power, promising the retention of Medibank, although following various changes, which gradually reversed the universality of the scheme, it became Medibank Private operating as a health insurance fund owned by the government in competition with other private insurers. The major changes were: October 1976 , a levy of $2.5 \%$ of taxable income was introduced on those without private insurance; May 1978, bulk-billing was restricted to pensioners and the socially disadvantaged, and the medical rebate was reduced to $75 \%$ of the scheduled fee; November 1978, the levy which penalized those without private insurance was abolished, and the rebate was reduced to $40 \%$ of the scheduled fee; May 1979, payment of rebates was restricted to services for which the scheduled fee exceeded Aus $\$ 20$; September 1981, rebates were reduced to $30 \%$ of the scheduled fee and were only paid to those with private medical insurance, and means-testing was introduced for free treatment in public hospitals (Duckett, 2007). Hence, by 1983, health care financing had returned to arrangements very similar to the pre-1974 situation. Free medical treatment was limited and often available at the discretion of the provider; public hospital treatment was only free to those with limited means. The privately insured were favoured through tax deductibility of premiums and a subsidy for rebates. Not surprisingly, private health insurance became a major source of finance, with around $70 \%$ of the population having both medical and hospital cover. Nonetheless, around $14 \%$ of the population had no insurance coverage or public entitlement, and were exposed to potentially major medical bills. The public were ill-informed and confused by the frequent changes to financing arrangements; their entitlements were altered not just by changes in Commonwealth policy but also by state-level changes in eligibility for public hospital treatment. By this time, Medibank and universal tax-financed hospital care had ceased. Medibank Private continued as the government-owned private insurer, operating under an independent but government-appointed board, and today it is the largest health insurance fund in Australia.

Medicare was introduced under another Labor government in 1984 and was very similar in design to the original Medibank (Duckett, 2007). Again, the introduction of a universal tax-financed scheme was accompanied by strong opposition from the medical profession 
(Crichton, 1990). This time there was much greater political stability and the structure of Medicare has remained intact. The coincidence of private insurance, private medicine and private hospital interests produced a strong coalition that found a political alliance. The Liberal Party retained its opposition to Medicare from 1984 until 1996, going into each election with a platform of repealing the universality and public financing of Medicare, limiting public financing to the disadvantaged, and encouraging private insurance. This was despite the clear strong public support for Medicare. It was not until 1996, after promising to continue Medicare, albeit with a complementary role for private insurance, that the conservative parties once again won a national election.

The original design of Medicare had not been explicit about the role of private insurance and private hospitals. There were those who argued for a laissez-faire approach, postulating that, if left alone, private insurance would decline until it reached a natural plateau, covering those who wished to buy the higher amenity of private hospital treatment. If this was the rationale, it is hard to see what the basis was for retaining community rating. However, community rating remained, with little or no discussion, let alone criticism, as part of making insurance affordable - perhaps a symbol of the Australian commitment to fairness. The alternative view was that the financial viability of Medicare required the coexistence of a strong private hospital sector, as the public system had never been intended to cope with the growing demands of the entire population. But if this rationale is accepted, there is no clear case for the universality of Medicare, which is considered to be a critical feature of the scheme.

\section{The private health insurance incentives strategy: 1996-2006}

At the time of the return of a Liberal government in 1996, private insurance was restricted to offering cover for private hospital treatment (it comprised both care in private hospitals and private care in public hospitals; it also covered day-only admissions in free-standing day-surgery facilities and a range of ancillary services, such as dentistry, optometry and physiotherapy) (Hall \& Savage, 2005). As noted above, premiums were community-rated and almost all insurers were required to accept all customers. The 1996 to 2007 era was marked by consolidation of registered insurance funds operating in Australia (PHIAC, 2016). In the period between 1995 and 2010, the number of insurance funds fell from 49 to 37 . However, despite the large number of funds, the market was 
(and remains) highly concentrated with the largest four holding $85 \%$ market share; with Medibank Private and the British United Provident Association (BUPA) Group having market shares in excess of $25 \%$ each.

Private health insurance coverage had reached a low of $32 \%$ of the population in 1996. Although this coverage was low in historical terms for Australia, it was nonetheless high compared with, for example, the United Kingdom, where fewer than $10 \%$ chose to buy private insurance rather than rely solely on the National Health Service. The private health insurance incentives strategy commenced in 1997 with the introduction of a subsidy for low-income earners to purchase insurance and a tax surcharge ( $1 \%$ of taxable income) for high-income individuals without private insurance. Hence it was termed the "carrots and sticks" policy. The estimated cost to government was Aus $\$ 600$ million per annum [or $11.5 \%$ of the Australian government's outlay on public hospitals at that time (Hall, 2001)]. This measure, however, seemed to have no impact on the trend of falling coverage.

The second step was introduced in January 1999. The "carrot" was extended to a $30 \%$ rebate on insurance premiums without any means test. It was initially estimated to cost Aus $\$ 1.5$ billion per annum but this figure was then revised to Aus $\$ 2.1$ billion in the second year. The second stage of the policy - the $30 \%$ rebate - was associated with a flattening of the downward trend and the level of insurance coverage stabilized. Lifetime Health Cover, the third step introduced in July 2000 in addition to the rebate and the tax surcharge, involved modifying community rating to allow for age-related premiums to be charged to those taking out insurance after the age of 30 . The base premium was increased by $2 \%$ for each year beyond 30 , but the rate was locked in at the rate at which people first purchased insurance. The aim of the scheme was to encourage the young, with relatively good risk profiles, to buy private insurance and maintain it for life. Although this measure constituted a major change in the structure of health insurance, it involved little or no cost to the government. Community-rated premiums had been accepted as a permanent feature of insurance regulation over the previous 50 years, despite other changes in policy. At the same time, provisions were made to encourage private insurance to offer "nogap" or "known-gap" policies to limit unforeseen out-of-pocket costs, essentially introducing complementary insurance for the co-payment component of in-hospital medical fees. Insurance coverage increased following Lifetime Health Cover so that by the end of 2000, insurance 
coverage had reached $45 \%$, almost a $50 \%$ increase on its 1996 low. In 2005 , the rebate was increased for older people, to $35 \%$ and $40 \%$ for people aged over 65 and over 70, respectively. An obvious consequence of this increase in coverage plus more generous support for older people was an increase in the cost of the rebate to Aus $\$ 3.6$ billion or $10 \%$ of Australian Government spending on health (AIHW, 2009).

There is one more avenue of health-insurance-related government spending that warrants a brief comment. The increasing concern with the growing level of co-payments, particularly in general practice, was the impetus for the introduction of the Medicare Safety Net in March 2004. The Safety Net covers out-of-hospital medical services for which medical benefits are paid (that is, services covered by Medicare). Once a specified level of co-payments has been reached, all further co-payments are reimbursed at $80 \%$, leaving individuals and families with $20 \%$ in out-of-pocket expenses. This represents a major change to the previous health insurance arrangements, as public funding is no longer restricted to the scheduled (that is, government-determined) fee but will apply to whatever fee the doctor will actually charge. Following the introduction of the Safety Net, there has been little change in patient co-payments but major changes in fee levels. This resulted in a far higher liability for spending than had been predicted; for every Safety Net dollar spent, around 70 cents went to providers in higher fees. Further, the changes in fee levels have been most marked for specialist providers, in particular for private obstetrics and assisted reproductive services (Van Gool et al., 2009). Indeed, the Safety Net has made out-of-hospital practice more lucrative for some providers than in-hospital services. As a result, there is clear evidence among some specialist groups that they are switching fees and services away from the inpatient sector covered by private health insurance and towards the out of-hospital sector that is covered by public funding. As technologies develop and enable more procedures to be delivered in the out-of-hospital sector, this practice may become more widespread and, as a result, will place additional strain on public financing.

\section{The effectiveness of the private health insurance strategy}

The question of whether the incentives achieved their intended objective is not clear-cut, simply because there was never an agreed and clear statement of the objective. At the time the strategy was developed, the 
government argued that increasing private insurance coverage would reduce public hospital use (Australian Government, 2007); and that this would be the case was reinforced by the popular media (Haas et al., 2001; Hall, 2001). However, over time, the objective was transformed into providing additional choice for private insurance (Australian Government, 2007). Whether Australians do in fact value this form of improved choice is hard to assess. Nonetheless, the introduction of the incentives was followed by a dramatic increase in the proportion of the population with private insurance. Private health (hospital) insurance coverage reached its lowest level in 1998, with $30.2 \%$ of the population holding hospital insurance in December 1998. By December 2000, population coverage reached $45.4 \%$. This was a major increase in the number of people with private health insurance. Hence, on the simplest measure (and the one used by the government in assessing its performance), the strategy was extremely successful. A more interesting question is which component of the strategy was effective. The private health insurance rebate has been one of the most controversial pieces of legislation due to the large costs. The most recent AIHW (2016a) data reveals that the rebate costs the Australian Government around Aus $\$ 5.7$ billion annually (representing around 9\% of its total spending on health) yet it apparently had little effect on insurance coverage. It was the third stage, Lifetime Health Cover, that was accompanied by the jump in coverage; indeed the cut-off date for insurance enrolment without the age-related premium had to be extended as the insurance companies simply could not handle the number of new customers. Lifetime Health Cover was simply a regulatory change, whereas the $30 \%$ rebate was costly because it required a substantial and ongoing windfall gain to the $30 \%$ of the population already holding private insurance. Lifetime Health Cover was accompanied by a very aggressive advertising campaign, under the slogan "Run for Cover", so there was both a price impact (expected future increases above the base premium) and a non-price impact. It is likely that some were frightened into buying insurance, some believed that they were buying in at a premium that would remain stable for the rest of their lives, while many were just confused.

The timing of the introduction of the rebate and Lifetime Health Cover - both were introduced over a 12 -month period - is such that it is very difficult to disentangle their effects. Butler (2002) argued, on the basis of the aggregate data, that the $30 \%$ rebate was costly and largely ineffective while Lifetime Health Cover was inexpensive and 
effective. Frech, Hopkins \& Macdonald (2003), using aggregate data, concluded that the regulatory change had more impact than the rebate, but that the rebate was still significant in increasing demand for private health insurance. In contrast, Palangkaraya \& Yong (2005), modelling individual decision-making using data from the National Health Survey and simulating the effects of policy change, concluded that Lifetime Health Cover was responsible for around $42 \%$ of the increase in private health insurance. Ellis \& Savage (2008), using a similar approach and the same data set, noting that Lifetime Health Cover in fact changes the future price of private health insurance, find an effect of the nonprice aspects of the policy, particularly for younger age groups. They attribute this effect to the advertising campaign. They concluded that the rebate reinforced the effect of Lifetime Health Cover for single people, but it weakened its effect for families in that it also reduced the future price of insurance.

\section{Adverse selection, hospital use, cost to government}

The design of Lifetime Health Cover was aimed at reversing adverse selection, which was widely perceived to be a key and critical feature of the Australian health care system (see in particular, Industry Commission, 1997). As the evidence for adverse selection was based strongly on the changing age profile of the insured, the solution was to provide an incentive for people to buy insurance before the age of 30 and then maintain it. The majority of new entrants to the private insurance pool following the incentives were under 65 years of age. The proportion of people aged 65 years and over in the insured population decreased from $14.9 \%$ in December 1998 to $10.4 \%$ in December 2000, although it had increased again to $14.0 \%$ in 2008 (PHIAC, 2010).

Barrett \& Conlon (2003) investigated the extent of adverse selection in health insurance and concluded that, measuring the health risk by the number of chronic conditions, adverse selection had increased over the 6 years before the introduction of the insurance incentives strategy. However, they also found evidence of better health risks selecting into insurance. This selection was based on self-assessed health status and risky behaviours (such as smoking or alcohol consumption); a finding confirmed by Doiron, Jones \& Savage (2008) using more recent data. Vaithianathan (2004) argued that community rating in Australia could in fact be circumvented, as insurers market different insurance plans 
with coverage designed to appeal to different risk groups, for example by offering plans excluding cataract surgery and joint replacement.

More insight into why people buy health insurance is provided in an analysis by Fiebig, Savage \& Viney (2006) using data collected since the introduction of the incentives. Insurance purchasers were categorized according to their reasons for purchasing health insurance. Security and peace of mind were identified as the only reasons for buying insurance by $24 \%$ of purchasers. For $13 \%$ of purchasers, choice of private hospital and doctor was key, $15 \%$ of purchasers were driven by financial reasons and the other categories comprised people who valued various combinations of the above factors. It should be noted that the combination of the rebate on insurance premiums and the income tax surcharge meant that many above-average income earners faced a negative price for insurance. In other words, they saved money by buying insurance and thereby avoided the additional income tax levy. Those driven by "security" reasons were likely to have held their insurance for 5 years or more before the introduction of the incentives, whereas those motivated by financial reasons were much more likely to buy insurance only after the incentives were introduced (Fiebig, Savage \& Viney, 2006).

Having private insurance does not necessarily equate with the use of the private system. All residents are entitled to free public hospital care. Fiebig, Savage \& Viney (2006) showed that those who bought insurance for financial reasons were less likely to choose the private system when admitted to hospital than those who valued choice and had held insurance since before the recent introduction of incentives. Vaithianathan (2002) stressed the importance of individuals who have been historically self-insured. They have a preference for private care but have felt that private health insurance has not offered them good value, presumably because they tend to be younger, healthier and wealthier than the average population. These individuals may be enticed into purchasing private health insurance by policy changes but their choice of hospital treatment may not change because they would have used the private health system irrespective of their insurance status.

Private hospital use did indeed rise following the expansion of private insurance. This has been taken as a measure of policy success by the government, which had set a goal of increasing private admissions as a proportion of total (public and private) hospital admissions. Some analysts have argued that this represents a welfare improvement, based on the assumption that every private admission has replaced a public 
admission (see for example Hopkins \& Frech, 2001; Frech, Hopkins \& Macdonald, 2003; Harper, 2003). However, it is not clear whether the share of private admissions would have actually remained unchanged if private insurance had not expanded, as private hospital use had also been rising throughout the period in which private health insurance coverage was falling. Private and public hospitals are not perfect substitutes. The highly specialized and university teaching hospitals are public hospitals; almost all emergency departments are located in public hospitals. Although there has been a concomitant change in the nature of private hospitals with increasing ownership by for-profit corporations, increasing case-mix severity and the availability of more sophisticated facilities, elective admissions are still the main focus of private hospital activity. Further, there is a moral hazard effect; that is, the purchase of private insurance encourages the over-use of the services covered by insurance. Several studies have shown that the insured are much more likely to be high users, though this is difficult to disentangle from adverse selection. The study by Savage \& Wright (2003) using data from the National Health Survey showed a substantial effect on increased length of hospital stay due to moral hazard associated with insurance whereas Doiron, Fiebig \& Suziedelyte (2014), using detailed administrative data, found large moral hazard effects but only for elective procedures.

The cost of subsidizing private health insurance continued to grow, from Aus $\$ 2$ billion in 2000-2001 to almost Aus\$5.7 billion in 20142015 (AIHW, 2006, 2016a). However, there was no evidence of reduced pressure on public hospitals, as demonstrated by increasing workloads. It has been argued that, given there were already substantial waiting lists particularly for elective surgery, a decrease in public hospital activity should not have been expected and that the increased throughput of the total hospital system, in terms of shorter waiting times, represents a real welfare gain (Frech \& Hopkins, 2004). It is then necessary to ask whether the insurance subsidies represent the most efficient means of achieving those gains. Lu \& Savage (2006), using the estimated reductions in Medicare admissions and hospital days, find that the average cost of a private admission produced by the private insurance incentives amounted to Aus $\$ 28606$ in 2001-2002. The actual average cost of a public hospital admission in that year was Aus\$28 61 (Lu \& Savage 2006). As private hospitals appear to be at best as efficient in producing episodes of hospital care as public hospitals, at least the same expansion of capacity could have been managed through the public 
system (Duckett \& Jackson 2000). This would have avoided the moral hazard problem associated with private insurance as shown by longer hospitalizations, more intensive resource use and possibly higher admission rates (Robertson \& Richardson, 2000; Savage \& Wright, 2003). More recent work by Cheng (2014) simulates the impact of reducing the subsidies and finds that any resulting increase in public spending on hospital care would be substantially less than the cost savings associated with lower subsidies.

\section{New directions, stalled reform and policy uncertainty (2007 onwards)}

Since 2007, there have been four national elections and six changes of Prime Minister. The 2007 election resulted in a change of government (from Liberal to Labor). The Government changed again in 2013. In the intervening period, the Global Financial Crisis of 2007-2008 struck. Although Australia was much less affected than many other countries (Australian Bureau of Statistics, 2010), the aftermath has increased concerns about government budget deficits and increasing government spending.

The health issue in the 2007 election was funding for public hospitals, in contrast to the previous elections, where the policy distinction between the two parties was drawn around the role of private financing of health care and health insurance. The new Labor government embarked on a structural reform process, establishing an inquiry (the National Health and Hospitals Reform Commission) to develop a longterm plan for Australia's health system (National Health and Hospitals Reform Commission, 2009). However, the terms of reference excluded any change to the status quo of private insurance. After a long process of negotiation with state and territory governments a reform package was agreed some 18 months and a change of Prime Minister later (Council of Australian Governments, 2011).

The main features of the National Health Reform Agreement were: (i) an agreed level of national government funding for public hospital care which, for the first time tied Commonwealth government funding to the volume of hospital services delivered; (ii) public reporting of hospital performance; (iii) new local organizations called Medicare Locals, to take responsibility for filling gaps in and co-ordinating the primary care of a geographically defined population base. Arrangements 
for private health insurance, the Pharmaceutical Benefits Scheme and the Medicare Benefits Scheme remained unchanged. Although this did not represent a comprehensive plan for reform, it did provide a basis for further development to which all governments were committed (not generally easily accomplished in a federal system) (Hall, 2010). At the same time, the new Labor Government looked to the insurance rebates for savings. Over the 2010 and 2014 period, the Commonwealth Government introduced several measures including: (i) means-testing with four different tiers based on income and family composition; and (ii) restricting increases in the rebate (enacted under Labor but not effective until 2014). This latter measure has meant that the rebate is no longer tied directly to private health insurance premium rises, which have been increasing in excess of $5.5 \%$ per year since 2010 . The rebate is now calculated on the basis of a weighted average to changes in the consumer price index and private health insurance premiums. These measures have meant that the rebate has moved from a standard $30 \%$ subsidy to a more complex set of arrangements where any individual's private health insurance rebate entitlement is dependent on their income, family composition, age and inflation. Rebates currently range from $0 \%$ to $35.72 \%$; those with zero entitlement fall into income brackets which attract the financial penalty for not holding private health insurance.

This period also marks the start of serious change in the operating status of private health insurance funds. In $1995,96 \%$ of policies were issued by not-for-profit funds; by 2010 this share had fallen to $30 \%$ (PHIAC, 2016). This dramatic change reflects the ownership status changes of a number of large funds including: Medibank Private, which was converted to for-profit and then privatized by the Australian Government; MBF, which was purchased by BUPA in 2008; and NIB, which was publicly listed in 2007 . These changes have meant that government subsidies for private health insurance have a direct bearing on private investment returns.

After the change in government in 2013, the national sense of direction embodied in the National Health Reform Agreement did not last long. Many aspects of the Agreement and several new agencies were reversed and disbanded (Hall, 2015). The public hospital funding agreement was reversed, with the Commonwealth contribution to be much more limited in the future. For the Commonwealth Government, this reflects a need to improve the budgetary position by moving back to surplus. It had the effect of highlighting the imbalance between revenue 
bases of states and territories and their expected service provision, which although it affects many sectors of service delivery, is most stark for hospital services.

In response, the Commonwealth Government initiated a process to develop a white paper on reforming federal and state relationships with a major emphasis on health care reform. The Department of the Prime Minister and Cabinet released a draft issues paper which outlined a set of reform options that to some extent represented innovative ideas about future directions affecting federal, state and private health insurance funding arrangements. One option was a proposal for the Commonwealth Government to contribute to all hospital services regardless of whether they occurred in a public or private hospital (Prime Minister and Cabinet, 2015). However, these proposals have not progressed over the last 18 months and have been taken off the Council of Australian Governments' agenda. Similarly, proposed changes to the Medicare safety net have been "paused" (the word of Prime Minister at the time) while the Government considers wider aspects of health reform. These include a number of reviews that are generally very focused and specific. For example, the MBS review is a detailed investigation of the classification and scheduled fee for out-of-hospital services provided under Medicare without addressing the underlying issue of the incentives generated by fee for service provision (Hall et al., 2015).

Although the 2013 Liberal election promises included restoring the levels of the private health insurance rebate, this has not been implemented. Initially the income tiers that determined the level of insurance rebate were indexed annually. Indexation has been paused since 2015 until 2021, so further reducing the value of the rebate. Meanwhile, there has been an expansion of the products and range of services offered under private health insurance. New provisions from 2007 allowed private health insurance to cover hospital substitute services (such as hospital in the home) and chronic disease management programmes. Initial enthusiasm for chronic disease management appears to have peaked with the number of participants and value of benefits paid falling since 2012-2013. Insurers have also established or acquired other health businesses, with the provision of dental and optical centres and more recently primary care. Medibank Private was involved in a more controversial scheme whereby it entered into an arrangement with a primary care group to provide same-day access at bulk-billed rates for Medibank Private clients by paying an "administration fee" to the clinics. 
Controversy focused on whether such payments could be considered as private insurance cover for Medicare-funded primary care services and hence illegal. This pilot scheme has been discontinued but BUPA is progressing with opening its own primary care clinics, open to insured and non-insured patients.

The replacement of Medicare Locals with new regional organizations, Primary Health Networks, was designed to allow private health insurers to become operators of the Networks or to join consortia that would operate Networks. There are some partnerships involving insurers, but it seems that insurers are playing a minor role.

At this stage it is difficult to ascertain the impact of these latest private health insurance reforms. However, membership has fallen slightly from $47.4 \%$ to $47 \%$ of the population in the year to June 2016 , which is the first drop in membership numbers in 15 years. The fall is higher at younger ages (APRA, 2016). There have also been widespread reports that private health insurance members are downgrading their insurance policies, implying that they are switching to cheaper products with higher deductibles and greater restrictions. The extent to which patients admitted to public hospitals use their insurance (that is, choose to be admitted as private patients) is increasing, apparently encouraged by hospital policies. As a result the payout in benefits by private insurers is increasing at a faster rate than revenue; in 2012-2013 benefits increased by $9.1 \%$ while membership increased by only $2.2 \%$ (PHIAC, 2015b). This, plus the fact that the rebate is no longer directly linked to private health insurance premium increases, also appears to have put additional pressure on insurance funds to contain their costs.

Private health insurance continued to be unpopular with voters due to rising premiums and difficulty in understanding what was covered by different insurance products. In October 2015 the Commonwealth Minister for Health announced a review and called for public submissions. Although the consultation period was just 1 month, over 40000 responses were received. At the end of 2016, the Commonwealth Minister for Health affirmed that the review was proceeding and would deliver an insurance rating system of gold, silver and bronze products to inform consumers and deliver value for money (Minister for Health, 2016).

Another issue that is likely to affect the Government's capacity and political will to change insurance arrangements arose during the 2016 election campaign. The Government had determined to outsource the 
processing of Medicare claims, an administrative change rather than a significant policy change. At the end of the campaign, the Opposition used this to target voters with a message about the privatization of Medicare. Although inaccurate, the "Mediscare" was credited with being a major contributor to the closeness of the election result. Suggestions of privatization are now a potent political weapon. Not surprisingly, the new Commonwealth Minister for Health was quick to emphasize that the Government's long term health plan was based on a "rock-solid" commitment to Medicare (Minister for Health, 4 Feb 2017). It includes a commitment to a hospital system comprising public and private sectors. In another interview, the Minister provided a view of the Australian health system as consisting of the three pillars of the Pharmaceutical Benefits Scheme, Medicare, and private health insurance (The Australian 4 Feb 2017). This suggests that support for private health insurance will remain a political priority for the government.

\section{Conclusions}

Sax, a well-respected bureaucrat and commentator on the Australian health system, described the evolution of health policy in Australia as "a strife of interests masquerading as a contest of principles" (Sax, 1984); and this is no more so than in the confusing and often ambiguous interplay around private health insurance. The focus on insurance since the 1980s has taken place at the expense of other aspects of the health system. When Medicare was established, there was a much clearer separation between hospital care and care in the community and the financial structure underlying them. This structure is not well designed for the coordination of care across hospitals and out-of-hospital services, for coordination across multiple providers, for the long-term management of chronic diseases, or for treatments that require complementary procedures, aids or prostheses and pharmaceuticals. Rather than have a substantial re-design of the system, each problem has been dealt with separately. For example, dental care has been traditionally excluded from Medicare. It is provided privately but private health insurance offers limited cover. There has been a range of very limited public subsidies or public programmes for dental care aimed at the most disadvantaged. Services provided by professionals other than medical practitioners have been excluded from Medicare. Hence, in primary care, employment of nurses has been very limited compared with many other countries. 
Services such as physiotherapy, speech therapy and other related health care are partially covered by insurance, depending on the policy type. The uninsured must either pay out of pocket or wait for limited public services. Consequently there has been a piecemeal approach to introduce small fixes and new spending programmes. As the Industry Commission had previously commented:

In undertaking reforms, governments have had a number of objectives, some of which are incompatible. Ad hoc and piecemeal reforms to a complex, interactive system can have some beneficial effects, but also can create further tensions and the need for additional government interventions. The outcome is a system that, despite numerous policy changes, has inherent and unresolved tensions (Industry Commission, 1997).

As a result, Australia has so far failed to address the fundamental pressures of the health system. Whether a new coherent vision will develop to guide further reform remains to be seen. The strife between public and private interests is as yet far from resolved and the contest of principles is likely to continue.

\section{References}

Australian Bureau of Statistics (2010). The global financial crisis and its impact on Australia. Year Book Australia, 2009-10: www.abs.gov.au/ AUSSTATS/abs@.nsf/Lookup/1301.0Chapter27092009\%E2\%80\%9310, accessed on 13/01/2017.

Australian Government (2007). Budget 2007-08, Budget Papers No. 1-4. Canberra, Commonwealth of Australia.

AIHW (Australian Institute of Health and Welfare) (2006). Health expenditure Australia 2004-05. Health and welfare expenditure series No. 28, Cat. no. HWE 35. Canberra, AIHW.

AIHW (2009). Health expenditure Australia 2007-08. Health and welfare expenditure series no. 37. Cat. no. HWE 46. Canberra, AIHW.

AIHW (2015). Health expenditure Australia 2013-14: analysis by sector. Health and welfare expenditure series no. 55. Cat. no. HWE 65. Canberra, AIHW.

AIHW (2016a). Health expenditure Australia 2014-15. Health and welfare expenditure series no. 57. Cat. no. HWE 67. Canberra, AIHW. 
AIHW (2016b). Admitted patient care 2014-15: Australian hospital statistics. Health and welfare expenditure series no. 68. Cat. no. HSE 172. Canberra, AIHW.

APRA (Australian Prudential Regulatory Authority) (2016). Private Health Insurance Annual Coverage Survey: www.apra.gov.au/AboutAPRA/Pages/ Default.aspx, accessed on 19/12/2016.

Barrett GF, Conlon R (2003). Adverse selection and the decline in private health insurance coverage in Australia: 1989-95. The Economic Record, 79(246):279-96.

Butler JR (2002). Policy change and private health insurance: did the cheapest policy do the trick? Australian Health Review, 25(6):33-41.

Cheng TC (2014). Measuring the effects of reducing subsidies for private health insurance on public expenditure for health care, Journal of Health Economics, 33:159-79.

Council of Australian Governments (2011). National Health Reform Agreement 2011: www.yourhealth.gov.au/internet/yourhealth/publishing .nsf/Content/nhra-agreement; accessed on 19/12/2016.

Crichton A (1990). Slowly taking control? Australian governments and health care provision, 1788-1988. Sydney, Allen and Unwin.

Department of Health (2015/2016). www.health.gov.au/internet/main/ publishing.nsf/Content/phiconsultations2015-16, accessed on 04/01/2017.

Doiron D, Fiebig DG, Suziedelyte A (2014). Hips and hearts: the variation in incentive effects across hospital procedures. Journal of Health Economics, 37:81-97.

Doiron D, Jones G, Savage E (2008). Healthy, wealthy and insured? The role of self-assessed health in the demand for private health insurance. Health Economics, 17(3):317-34.

Duckett SJ (2007). The Australian health care system, 3rd edition. Melbourne, Oxford University Press.

Duckett SJ, Jackson TJ (2000). The new health insurance rebate: an inefficient way of assisting public hospitals. Medical Journal of Australia, 172:439-42.

Ellis RP, Savage E (2008). Run for cover now or later? The impact of premiums, threats and deadlines on private health insurance in Australia. International Journal of Health Care Finance, 8(4):257-77.

Fiebig D, Savage E, Viney R (2006). Does the reason for buying insurance influence behaviour? CHERE Working Paper 2006/1. Sydney, CHERE.

Frech HE, Hopkins S (2004). Why subsidise private health insurance? Australian Economic Review, 37(3):243-56. 
Frech HE, Hopkins S, Macdonald G (2003). The Australian private health insurance boom: was it subsidies or liberalised regulation? Economic Papers, 22(1):58-64.

Haas M et al. (2001). The news on health care costs: a study of reporting in the Australian print media for 1996. Journal of Health Services Research and Policy, 6(2):78-84.

Hall J (2001). The public view of private health insurance. CHERE Discussion Paper 45. Sydney, CHERE.

Hall J (2010). Health care reform in Australia: Advancing or side-stepping? Health Economics, 19(11):1259-63.

Hall J (2015). Australian health care - the challenge of reform in a fragmented system. New England Journal of Medicine, 373:493-7.

Hall J, Savage E (2005). The role of the private sector in the Australian health care system. In: Maynard A, ed. The public-private mix for health. London, Nuffield Provincial Hospitals Trust.

Hall J et al. (2015). Medicare review must deal with 'elephant in room'. The Conversation: https://theconversation.com/medicare-review-must-dealwith-elephant-in-the-room-incentives-40819; accessed on 19/12/2016.

Harper I (2003). Preserving choice: a defence of public support for private bealth care funding in Australia. Commissioned by Medibank Private Limited. Melbourne, Harper Associates.

Hopkins S, Frech HE (2001). The rise of private health insurance in Australia: early effects on insurance and hospital markets. Economic and Labour Relations Review, 12(2):225-38.

Industry Commission (1997). Private health insurance. Canberra, AGPS.

Lu M, Savage E (2006). Do financial incentives for supplementary private health insurance reduce pressure on the public system? Evidence from Australia. CHERE Working Paper 2006/11. Sydney, CHERE.

Minister for Health (2016). Transcript of doorstop Parliament House. 19 October 2016 www.health.gov.au/internet/ministers/publishing.nsf/Content/ health-mediarel-yr2016-ley161019.htm; accessed on 20/12/2016.

Minister for Health (2017). Transcript of doorstop Melbourne. 4 February 2017 www.greghunt.com.au/Media/MediaReleases/tabid/86/ID/4145/ Doorstop--Melbourne.aspx; accessed on 5/07/2017.

National Health and Hospitals Reform Commission (2009). Final Report. A Healthier Future for All Australians. Canberra, Commonwealth of Australia. Palangkaraya A, Yong J (2005). Effects of recent carrot-and-stick policy initiatives on private health insurance coverage in Australia. Economic Record, 81(254):262-72. 
Pearce AM et al. (2012). Delays in access to affordable medicines: putting policy into perspective. Australian Health Review, 36(4):412-18.

PHIAC (2010). Operations of Private Insurers Annual Report 2009-10.

Canberra, Private Health Insurance Administration Council.

PHIAC (2015a). Report March 2015: www.apra.gov.au/PHI/PHIAC-Archive/ Documents/PHIACAaust-Mar15.pdf; accessed on 03/01/2017.

PHIAC (2015b). Operations of the Private Health Insurers. Annual Report 2013-14: www.apra.gov.au/PHI/PHIAC-Archive/Documents/Operationsof-PHI-Annual-Report-2013-141.pdf; accessed on 19/12/2016.

PHIAC (2016). Competition in the Australian Private Health Insurance Market: www.apra.gov.au/PHI/PHIAC-Archive/Documents/Competitionin-the-Australian-PHI-market_June-2015.pdf; accessed on 03/01/2017.

Prime Minister and Cabinet (2015). Reform of the Federation: discussion paper 2015; https://federation.dpmc.gov.au/publications/discussion-paper; accessed on 19/12/2016.

Robertson IK, Richardson JR (2000). Coronary angiography and coronary artery revascularisation rates in public and private hospital patients after acute myocardial infarction. Medical Journal of Australia, 173(6):291-5.

Savage E, Wright DJ (2003). Moral hazard and adverse selection in Australian private hospitals: 1989-90. Journal of Health Economics, 22(3):331-59.

Sax S (1984). A strife of interests: politics and policies in Australian bealth services. Sydney, Allen and Unwin.

Scotton RB (2001). The making of Medibank. In: Mooney G, Plant A, eds. Daring to dream: the future of Australian health care - essays in honour of John Deeble. Bentley, Black Swan Press.

The Australian. Hunt's priority: clear direction to save health. 4 February 2017.

Vaithianathan R (2002). Will subsidising private health insurance help the public health system? Economic Record, 78:277-84.

Vaithianathan R (2004). A critique of the private health insurance regulations. Australian Economic Review, 37(3):257-70.

Van Gool KC et al. (2009). Who's getting caught? An analysis of the Australian Medicare Safety Net. The Australian Economic Review, 42(2):143-54. 